Supporting Information

\title{
E-Cigarette Flavoring Chemicals Induce Cytotoxicity in HepG2 Cells
}

Brittany P. Rickard ${ }^{\dagger}$, Henry Ho ${ }^{\ddagger}$, Jacqueline B. Tiley ${ }^{\ddagger}$, Ilona Jaspers ${ }^{\dagger \S}$, Kim L. R. Brouwer ${ }^{\dagger *}$

${ }^{\dagger}$ Curriculum in Toxicology \& Environmental Medicine, UNC School of Medicine, The University of North Carolina at Chapel Hill, Chapel Hill, North Carolina, 27599-7325 USA.

Division of Pharmacotherapy and Experimental Therapeutics, UNC Eshelman School of Pharmacy, The University of North Carolina, Chapel Hill, North Carolina, 27599-7569 USA.

${ }^{\S}$ Center for Environmental Medicine, Asthma, and Lung Biology, UNC School of Medicine, The University of North Carolina at Chapel Hill, North Carolina, 27599-7310 USA.

\section{Corresponding Author}

*Kim L.R. Brouwer, UNC Eshelman School of Pharmacy, The University of North Carolina at Chapel Hill, CB \#7569 Kerr Hall, Chapel Hill, NC 27599-7569. Phone: (919) 962-7030. Fax: (919) 962-0644. E-mail: kbrouwer@unc.edu 


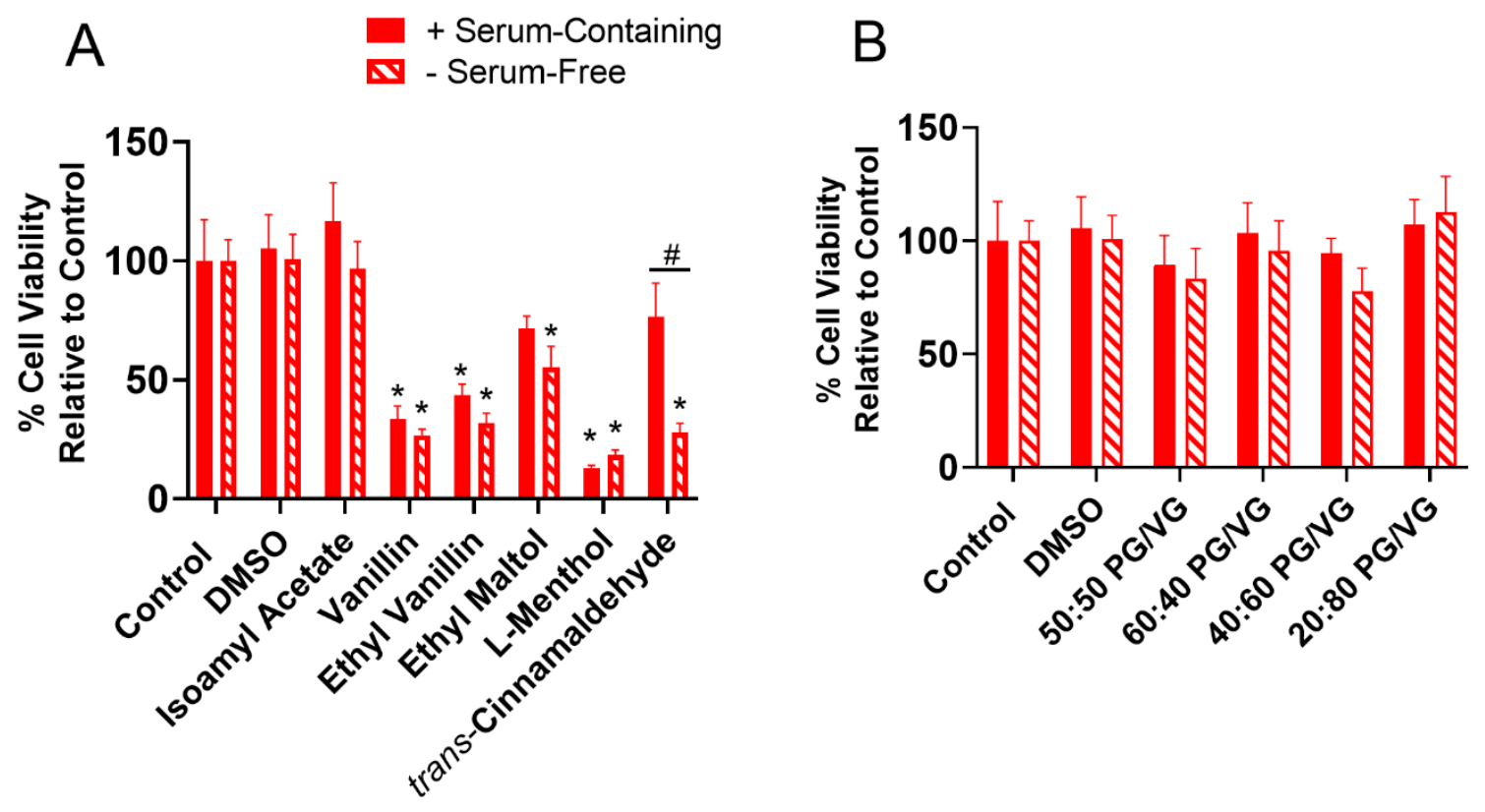

Figure S1. Cytotoxicity of E-Cigarette Chemicals after 30-Min Repeated Exposure. A) Effects of flavoring chemicals $(67.3 \mu \mathrm{M}$ isoamyl acetate, $5 \mathrm{mM}$ vanillin, $5 \mathrm{mM}$ ethyl vanillin, $5 \mathrm{mM}$ ethyl maltol, $5 \mathrm{mM} \mathrm{L}$-menthol, and $79.4 \mu \mathrm{M}$ transcinnamaldehyde) on HepG2 cells after repeated exposure. B) Effects of propylene glycol and vegetable glycerin (PG/VG) mixtures (50:50, 60:40, 40:60, 20:80) on HepG2 cells after repeated exposure. HepG2 cells were exposed to each flavoring chemical or PG/VG mixture in serum-containing (+) or serum-free (-) media every $30 \mathrm{~min}$ for $5 \mathrm{~h}$, followed by incubation with each flavoring chemical or PG/VG mixture for $43 \mathrm{~h}$ (total exposure time $=48 \mathrm{~h}$ ). Results are shown as mean $\pm \mathrm{SD}$ ( $\mathrm{n}=3$ individual experiments in triplicate in media \pm serum). Significance between control and each chemical or $\mathrm{PG} / \mathrm{VG}$ mixture \pm serum is denoted by $*(\mathrm{P}<0.05)$, and significance between + serum and - serum for each chemical or PG/VG mixture is denoted by \# $(\mathrm{P}<0.05)$ determined by a two-way ANOVA followed by Tukey's multiple comparisons test for correction. 


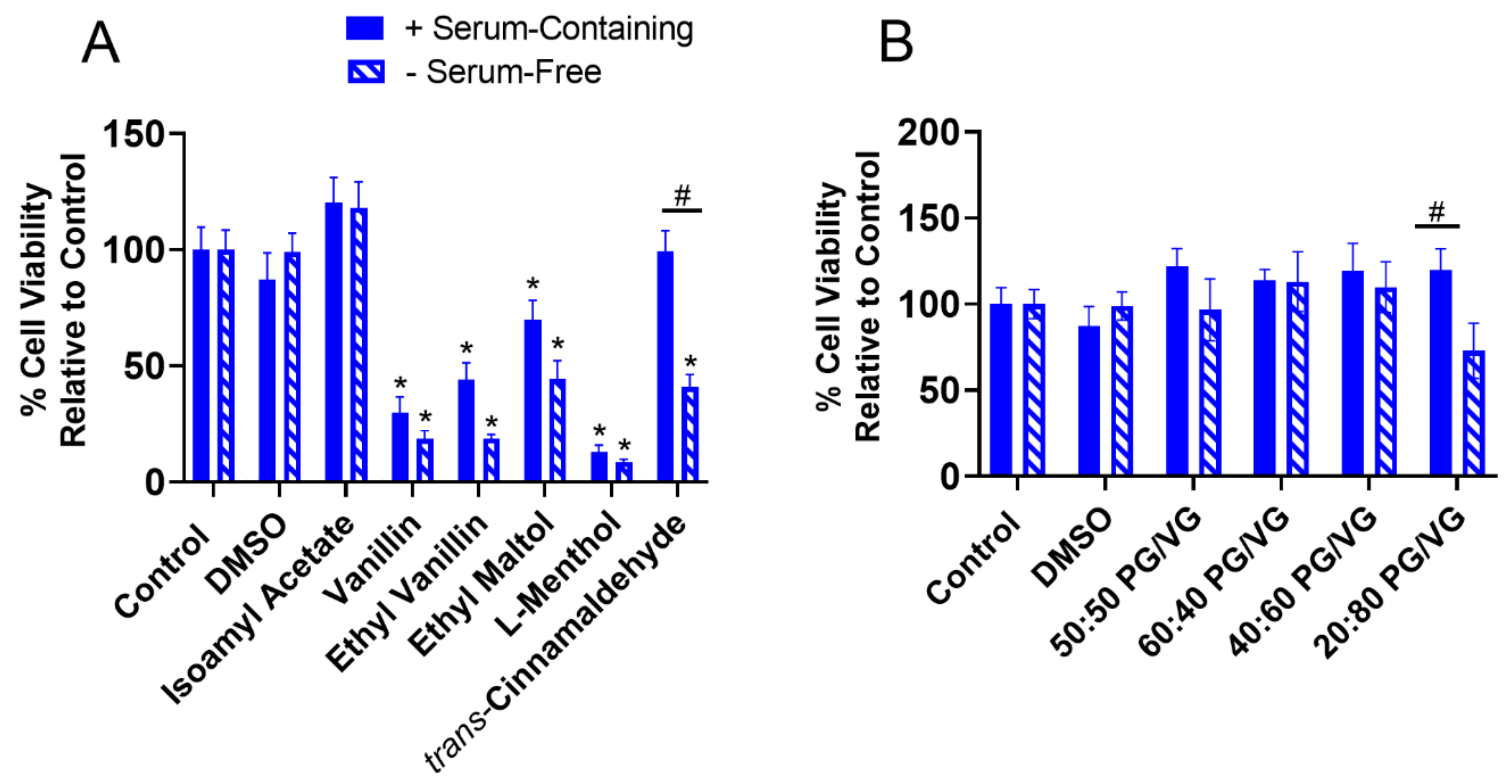

Figure S2. Cytotoxicity of E-Cigarette Chemicals after 90-Min Repeated Exposure. A) Effects of flavoring chemicals $(67.3 \mu \mathrm{M}$ isoamyl acetate, $5 \mathrm{mM}$ vanillin, $5 \mathrm{mM}$ ethyl vanillin, $5 \mathrm{mM}$ ethyl maltol, $5 \mathrm{mM}$ L-menthol, and $79.4 \mu \mathrm{M}$ transcinnamaldehyde) on HepG2 cells after repeated exposure. B) Effects of propylene glycol and vegetable glycerin (PG/VG) mixtures (50:50, 60:40, 40:60, 20:80) on HepG2 cells after repeated exposure. HepG2 cells were exposed to each flavoring chemical or PG/VG mixture in serum-containing (+) or serum-free (-) media every 90 min for 5 h, followed by incubation with each flavoring chemical or PG/VG mixture for $43 \mathrm{~h}$ (total exposure time $=48 \mathrm{~h}$ ). Results are shown as mean $\pm \mathrm{SD}(\mathrm{n}=3$ individual experiments in triplicate in media \pm serum). Significance between control and each chemical or $\mathrm{PG} / \mathrm{VG}$ mixture \pm serum is denoted by $*(\mathrm{P}<0.05)$, and significance between + serum and - serum for each chemical or $\mathrm{PG} / \mathrm{VG}$ mixture is denoted by \# $(\mathrm{P}<0.05)$ determined by a two-way ANOVA followed by Tukey's multiple comparisons test for correction. 